\title{
DESIGN AND IMPLEMENTION OF A BUILDING MANAGEMENT SYSTEM USING PROGRAMMABLE LOGIC CONTROL
}

\author{
Abdouslam M. Bashir \\ Higher Institute of Industrial Technology, \\ Tripoli-Libya
}

\begin{abstract}
This paper discusses the design and the implementation of a prototype for controlling a door, lighting system, window, air conditioner was designed and built. 6 modes were implemented to control the conditions of door security, air-conditioning and ventilation, lights in the prototype. a Siemens' programmable logic controllers PLC type (S7-1200) was used to design, simulate and generate a ladder routine program. other parts were assembled and connected to each other and. placed in one control panel which attached to the prototype frame. only authorized users are allowed to select any of the 6 modes mentioned above. The prototype was tested and some trials were run to validate the control capability of the prototype elements with satisfactory results were shown though energy saving tests are yet to be conducted. In addition some of resent technologies building management systems (BMS) were also reviewed.
\end{abstract}

Keywords - building management systems, building automation, Building Energy Management (BMS).

\section{INTRODUCTION}

Home automation is to connect various devices and systems in the home together so that they can be controlled from anywhere and create the desired interaction among them. The intelligent system controls lighting, heating, ventilation, air conditioning, security and safety, music, energy saving.

There are devices based on smart home system, including smart switches that replace traditional switches and smart sensors and others. For example, when you arrive at your home, your home automation system will automatically close the water dispenser, open the garage door, open the front door lock, disable the alarm, light up the stairs, and turn on the TV. With a simple push of the remote control button, all the equipment related to a certain "activity" can be activated, such as a movie display: the LCD will start working, the lights will be automatically dimmed, the curtains will be closed, all calls will be switched directly to the voicemail system as stated in a Wikipedia article (2016).

\author{
Feras Omar Askir \\ Higher Institute of Industrial Technology, \\ Tripoli-Libya
}

Smart home is an integrated system with advanced control devices - touch screens installed on the wall or mobile devices such as iPad and iPhone - and control buttons, which control and control all electrical and electronic devices in the home such as lighting, curtains, air conditioning, television, audio system and cameras, Electrical, anti-theft and fire protection systems.

\section{A. building automation}

Building Automation is an innovative term for each building that is self-operated by a computer network connected to electronic devices designed to control the systems of: fire, safety, lighting (especially emergency lighting), air conditioning/ heating, humidity and ventilation.

The basic function of the NAM system is to control the climate within a certain area, lighting operation based on room occupancy, monitoring the performance of all systems inside the building, sending alerts (usually via e-mail or text messages) to the maintenance staff in the building

A building with a sleeping system is usually referred to as a "smart building" or if an apartment building called a "smart home" and often a commercial / military building uses control systems to include and deepen the mechanical systems of residential buildings.

Most of the buildings conserving the environment use a growing system to control the energy, air and water inside the building. Based on the development and progress of ventilation and humidity systems, electronic devices and their response to demand became one of the traditional functions of a growing system. Even passive houses that do not consume energy permanently will need a system to control Shading, temperature recording, and timing of device usage as depicted by Mastery IT(2012). Most of the buildings that use a developing system have a basic bus and a secondary transmission connected to a control system, which in turn is divided by input and output units. Also, the user interface and usually the air conditioning, protection and lighting systems communicate with each other through the BACnet protocol. Nam "usually uses the network management protocol to follow up tasks, more related information provided in a Wikipedia article (2016). 


\section{International Journal of Engineering Applied Sciences and Technology, 2019 Vol. 4, Issue 6, ISSN No. 2455-2143, Pages 196-204 \\ Published Online October 2019 in IJEAST (http://www.ijeast.com)}

\section{B. Building management system}

The concept of control network has been adopted in Building Management Systems for over 20 years, as described by Derek et al.(1997). The system is a computer that maintains a monitoring system installed in buildings that control and monitor the mechanical and electrical building equipment such as ventilation, lighting, power systems, fire systems and protection systems.

A building management system consists of software and hardware; software is usually configured hierarchically and can be proprietary and used to the degree of protocols such as C-bus, Profibus and so on, However, new vendors are producing BMSs that integrate the use of Internet protocols and open standards such as DeviceNet, SOAP, XML, BACnet, LonWorks, and Modbus. Characteristics of the system Building management system is the most common in a large building. Its primary function is to manage the environment within the building and possibly control the temperature, levels of carbon dioxide and moisture inside the building.

As a basic function in most building management systems, it controls heating and cooling and manages systems that distribute this air throughout the building (eg. by operating fans or opening/ closing valves) and then dominates locally a mixture of heating and cooling to achieve a temperature Room requested. Secondary function is sometimes to monitor the level of carbon dioxide (CO2) generated from human, mixing in the external air with waste air to increase the amount of oxygen at the same time reduce heat / cooling losses.

Building Management System (BMS) systems typically account for $40 \%$ of building energy usage, and if lighting is added, this figure will be approximately $70 \%$. Building Management System (BMS) systems are a critical component of energy demand management. It is incorrect that BMS systems are believed to account for $20 \%$ of building energy use or approximately $8 \%$ of total energy use in the United States.

Building Management System systems are usually delivered as complete systems and services through companies such as Siemens, Honeywell, Johnson Controls, TrendControls, TAC, Tran and others. Independent service companies use solutions from companies such as Rockwell Automation, KMB, BPP Energies, Delta, Deystech, Sircon and KMC Controls (KMC). New, more flexible solutions that connect BMS systems and software project management include SAP, OpenView, Archibus, Maximo and other smaller companies, including Augusta Systems, Grid Logics, Network Harbor and North Building Technologies.

Bushby (2017) developed A standard communication protocol for building automation and control networks called BACnet TMwas setup to provide the communication infrastructure required to integrate products made by different vendors and to integrate building services including that are now independent.

Oti , et al (2016), A framework proposed to aid building design and operation data integration. It showed the relationship between building management systems and building information models can be established. Feedback loops from building energy consumption to inform and improve design and facility management in a BIM. The framework was thought to have contribution in closing gaps between the design, construction and operation phases of a building's life-cycle. On the other hand, presented a wide range of methods, as described by Pukīte (2017), of defining building management systems and building maintenance, stressing the need for a need for a more effective management system of the building lifecycle to provide sustainable residential property development. Some of the newer systems allow control of a plant such as boilers, air treatment units and cooling towers to be controlled by a simple graphical interface in a web browser.

\section{The Optimal use of energy}

This feature is achieved by automatically controlling home lighting (on / off, blackout), heating and cooling systems while away from home, 8which saves a lot of energy consumption. The user can monitor the home and control all systems through any Internet-connected device, such as a personal computer or smartphone. The smart home system makes a property more attractive to the customer and adds to its physical value. It can be possible to adjust and adjust the touch screen control to suit the tastes and requirements of different customers. Children can learn and understand how to use basic functions in the system. Daily activities are controlled by just one button, such as Daytime, Night, Vacation, or Exit Scenario button. In addition to other specialized activities such as temperature control, lighting, and sound systems

A review conducted by Yang et al. (2017) of building energy management systems was discussed extensively and focused on a multiple levels system from individual sensors and actuators to users' interface, to facilitate data collection, analysis, diagnose, trend finding, and decision-making.

Honold et al. (2017) focused their research on residential buildings specifically where a concept of a distributed integrated energy management was presented, which was mainly for reducing operational energy costs of the household at a rate dependent on user behavior and tariff structures.

This reduction of energy cost was confirmed by using neural networks to predictively control a commercial building energy management system, as demonstrated by Macarulla et al. (2017). Up to $20 \%$ of energy in proposed building was reduced by generating a neural network that turns on the boiler each day at the optimum time, according to the surrounding environment, to achieve thermal comfort levels at the beginning of the working day. 


\section{International Journal of Engineering Applied Sciences and Technology, 2019 Vol. 4, Issue 6, ISSN No. 2455-2143, Pages 196-204 \\ Published Online October 2019 in IJEAST (http://www.ijeast.com)}

A fuzzy-logic system developed by Rezeka et al. (2015) was also adopted to reduce energy consumption in buildings focusing on ventilation and air-conditioning system. Rooms in building can strategically divided into very important rooms, important rooms and normal rooms. The system claimed to adjust both temperature and humidity within the acceptable limits at different operating conditions. The intelligent Building Energy Management System (iBEMS) is another promising technique to manage building energy as mentioned by Papantoniou et al. (2017). The commercially used system adjusts automatically the operation of the systems using inputs from the installed sensors and from external data.

\section{Building Management Systems PRototype}

\section{A. THE FRAME}

It is a wire frame made of stee 1 in a cubic shape. Each part is assembled and connected by using the arc welding. The frame has $900 \mathrm{~mm}$ in length and width of mm830 with a height of $1200 \mathrm{~mm}$ as a sufficient volume to allow all required devices and wiring to fit in, as shown in Fig. 1.

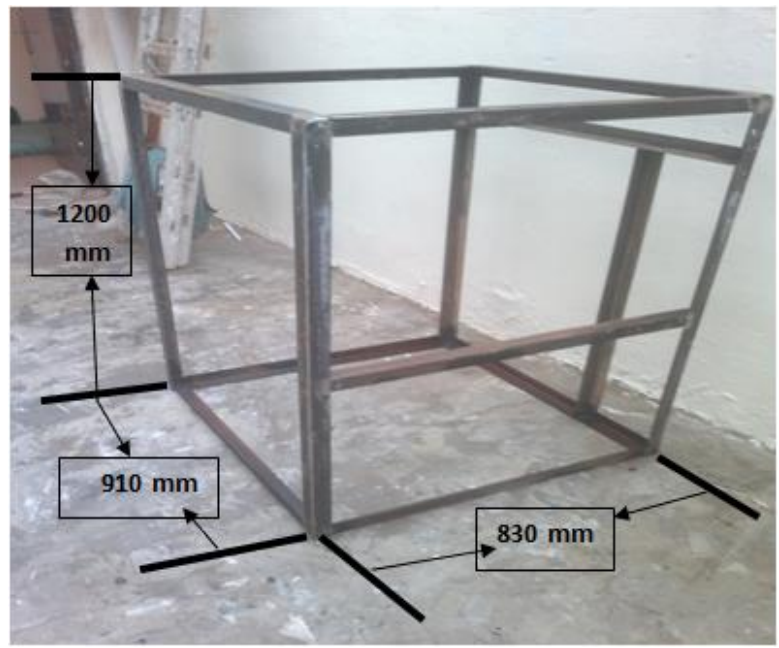

Fig. 1. The wire frame of the proposed prototype

1) Door

The main entrance door to the prototype is made of PVC material with $640.500 \mathrm{~mm} \times 1000 \mathrm{~mm}$ in dimension.

2) Door lock

Due to the lack of obtaining an off shelf electric lock suitable for door size in the market another method has been used to make the lock and opening the door electrically and the structure used was a metal rod with a diameter of $10 \mathrm{~mm}$ and a length of $70.500 \mathrm{~mm}$ connected to an iron plate of $220 \mathrm{~mm} *$ $10 \mathrm{~mm}$ and connected to an electric motor (12 v DC) by pushing or pulling the metal pins.

3) Window

The window is made of PVC material and dimensioned as $600 \mathrm{~mm} \times 600 \mathrm{~mm}$.The window closing and opening mechanism was motorized with a $12 \mathrm{v}$ DC motor, which has a mechanical switch to protect the window motor from damaging.

4) Fan

The ventilation fan is a commercial $220 \mathrm{v}$ AC with a $220 \mathrm{~mm}$ in diameter

5) Control box

Its dimension is $400 \mathrm{~mm} \times 500 \mathrm{~mm} \times 150 \mathrm{~mm}$ with a transparent face covering an area of $270 \mathrm{~mm} \times 400 \mathrm{~mm}$ made of plastic material. In the box all electronic parts of the control system are assembled, including:

1. PLC, which is a Siemens S7-1200 controller. The controller includes a microprocessor, an integrated power supply, input and output circuits, built-in PROFINET, highspeed motion control I/O, and on-board analog inputs in a compact housing to create a powerful controller.

2. Transformers (Step down transformer converting the voltage from $220 \mathrm{v}$ AC to $5 \mathrm{v} A C$ and then the output is connected to the circuit to switch from $5 \mathrm{v}$ AC to $5 \mathrm{v}$ DC. And another transformer converting the voltage from $220 \mathrm{v}$ AC to $12 \mathrm{v} A C$ and then the output is connected to the circuit to switch from the AC signal $12 \mathrm{v}$ AC to DC $12 \mathrm{DC}$.

\section{An Ardunio board.}

4. Two relays (a relay $24 \mathrm{v}$ DC_5v DC connecting a signal from the arduino to PLC, and a relay $12 \mathrm{v}$ DC_24vDC turning off the $12 \mathrm{v}$ DC power outlet for the door and the window. Fig. 2 depicts the locations of the control system main components.

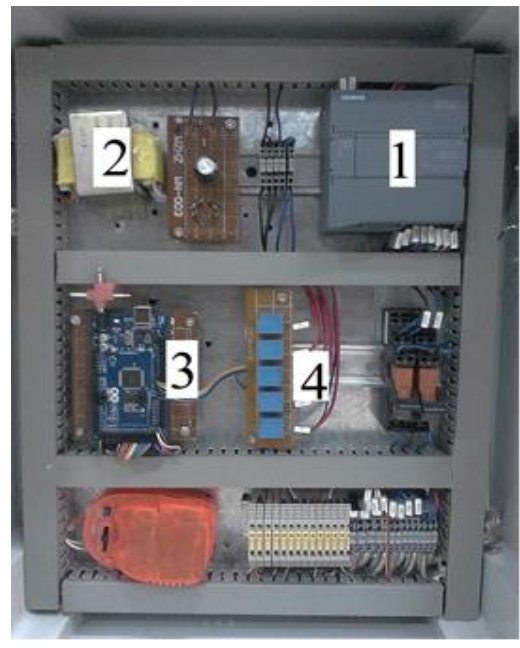

Fig. 2. The control system main elements

\section{6) Control pad}

The system control the password numb er and enter the options, Consisting of: Input panel with display to allow only those are authorized to access the prototype, which is 


\section{International Journal of Engineering Applied Sciences and Technology, 2019 \\ Vol. 4, Issue 6, ISSN No. 2455-2143, Pages 196-204 \\ Published Online October 2019 in IJEAST (http://www.ijeast.com)}

controlled by a an arduino board to set up passwords and options of the output units.

\section{7) DC motor:}

It is an electric motor that converts electrical energy to kinetic energy and works only on DC systems. It is characterized by high speed control and high torque especially when starting movement. Fig. 3 shows the main component of the prototype.

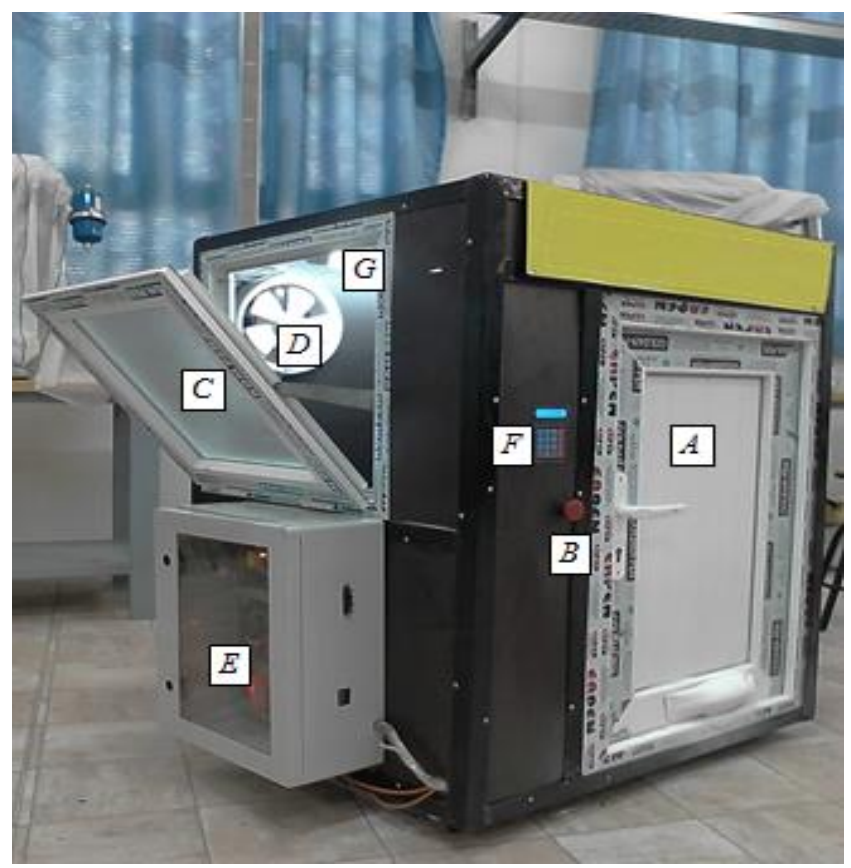

Fig. 3. Fig. 3.The prototype component

\section{B. THE CONTROL SYSTEM}

The system has a keyboard and an LCD screen, which starts by entering 4-digit PIN number, which is compared to the programming (for authorized users only). If the number is wrong, an error message is displayed and asked to enter the correct PIN again. After three false attempts, an alarm "Buzzer" is sounded. When user is successfully logged in to the system, another message requesting to enter entering one of the pre defied defined options (A, B, C, D, and G) for which a specific function is selected, as to be explained later on.

Having entered the desired option, the system functions within day the working hours in a given specific time of a working day. None the less, the system can only allow the chosen option to be changed by entering the PIN number

\section{THE SYSTEM OPTIONS}

Option 'A' once selected, the prototype door opens, followed by overhead lights will go on and any air conditioner of fan(s) in the box will turn on automatically in a sequence respectively. Fig.4 through 7 illustrate option ' $A$ ' and its functioning sequences in the ladder routine program.

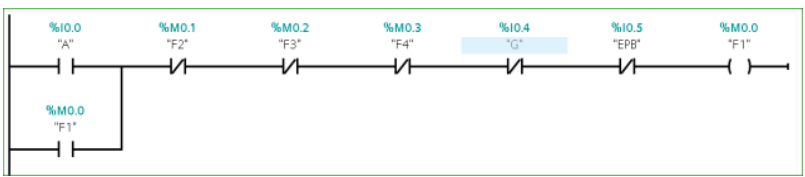

Fig. 4. Option 'A'

1. Opening the door .

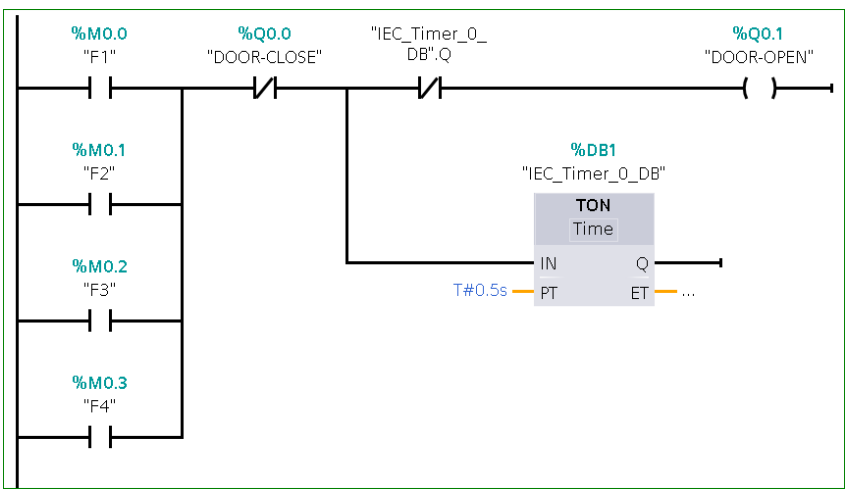

Fig. 5. The prototype door opens

1. Turning on lights.

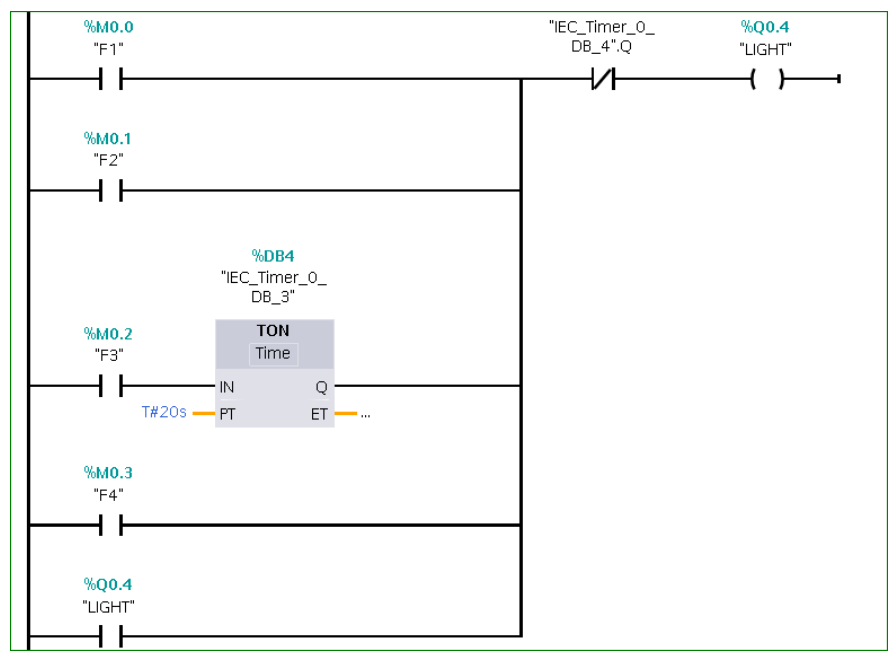

Fig. 6. . All overhead lights are on 


\section{International Journal of Engineering Applied Sciences and Technology, 2019 \\ Vol. 4, Issue 6, ISSN No. 2455-2143, Pages 196-204 \\ Published Online October 2019 in IJEAST (http://www.ijeast.com)}

2. Operation of air conditioners (provided that the window is closed).

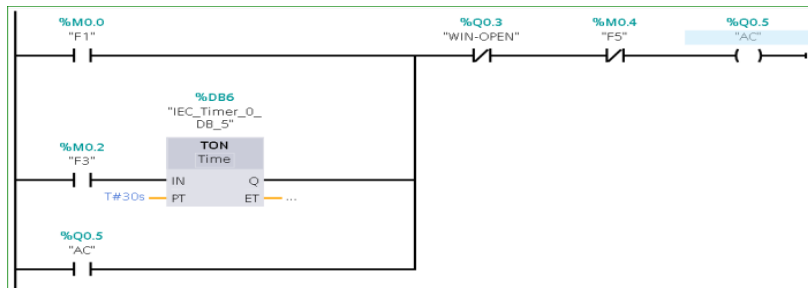

Fig. 7. Any fans or air conditioners are switched on

Option ' $B$ ': once selected, again the prototype door opens and overhead lights are on similar to option ' $A$ ' but the air conditioner is not activated. Instead, the prototype windows are open automatically, as shown in Fig. 8.

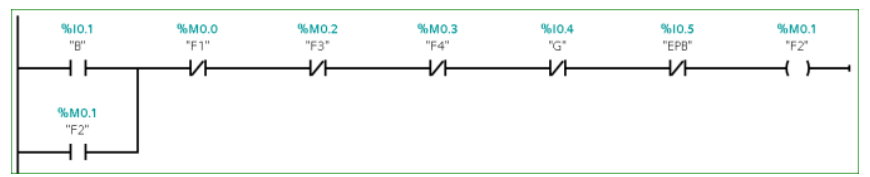

Fig. 8. Option 'B'

This option is design in case of power cut-offs. Fig.9 illustrates option ' $\mathrm{B}$ ' and its windows' control function in the ladder routine program.

1. Open a window with a closed air condition.

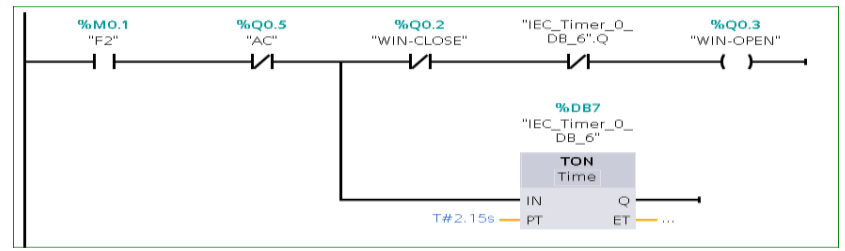

Fig. 9. All windows are automatically open

Option ' $C^{\prime \prime}$ : this option is deigned in case of electrical power fluctuation of using fuel run electric generator, in which each function is turned on or off at a specific time. Opening the prototype is similar to that in option ' $A$ ' and ' $B$ '. Fig.10 through 12 illustrate option ' $\mathrm{C}$ ' and its functioning sequences in the ladder routine program.

1. Opening the door .

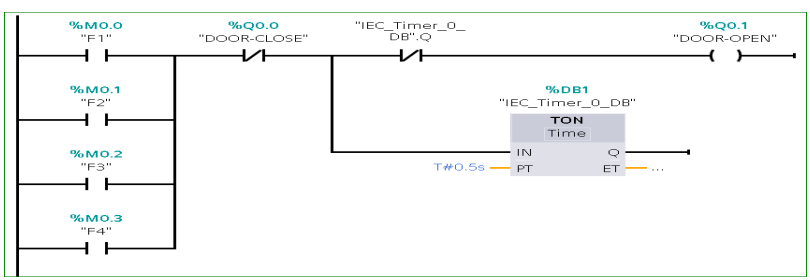

Fig. 10. Fig. 10. Opening doors in option ' $\mathrm{C}$ '
2. Waiting for 10 seconds turn on the lighting.

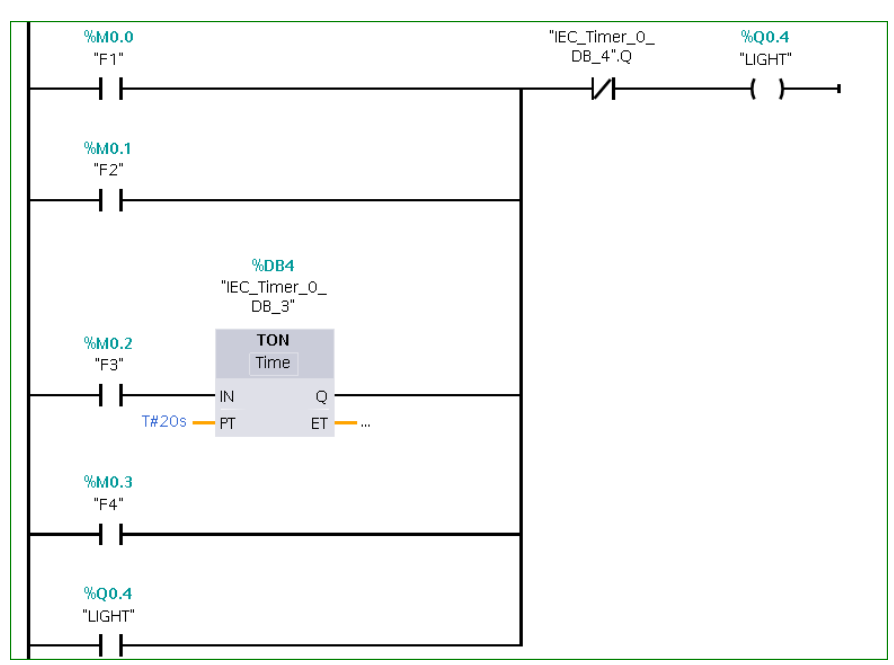

Fig. 11. After 10 seconds, all lights are on

3. Waiting for 5 seconds, then turn on the air conditioner with all window are closed.

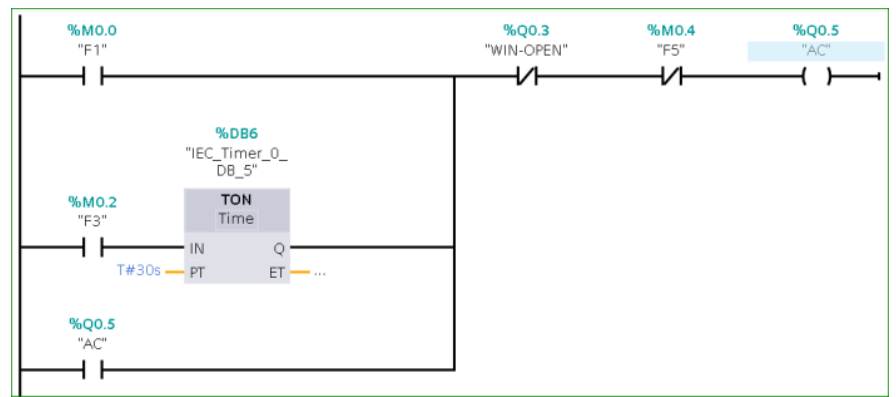

Fig. 12. Watermark embedding algorithm Block Diagram

Option 'D: this option deals only with any overhead lightning and controlling door mechanism. Using fans or air conditioning are not considered in this option. Fig. 13 and 14 show opening the door and turning on the overhead respectively.

1. Opening the door

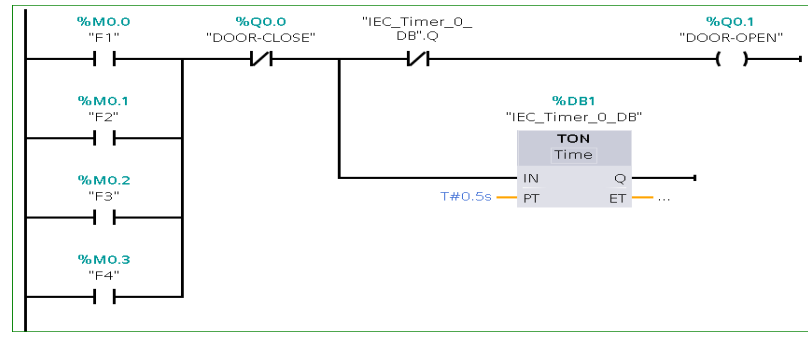

Fig. 13. Opening doors in option ' $\mathrm{D}$ ' 
2. Turning on lights

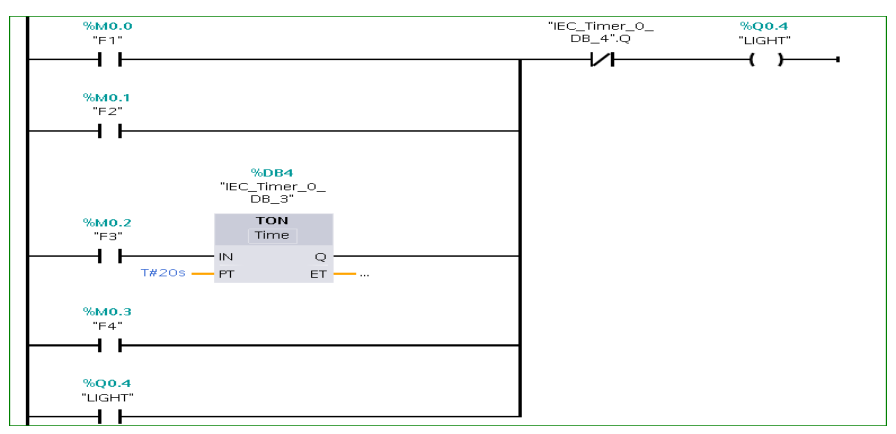

Fig. 14. .All lights are on in option 'D'

Option ' $\mathrm{G}$ ': this option is mainly used in case of emergency where it shuts off and any devices, door or window in the prototype, as shown in Fig. 15 through 19.

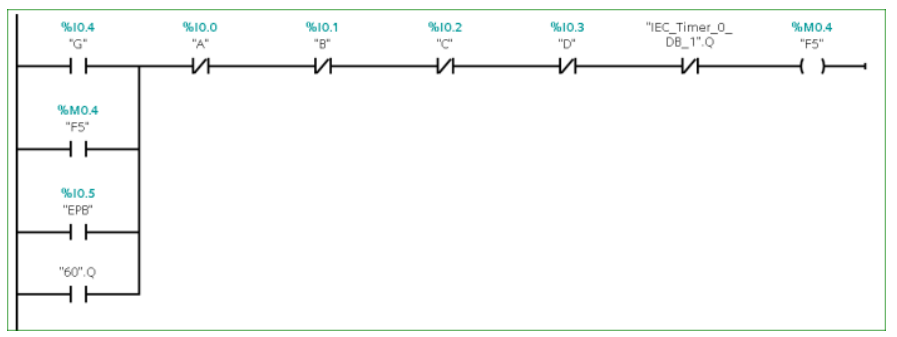

Fig. 15. Option 'G'

1. Turn off air conditioner.

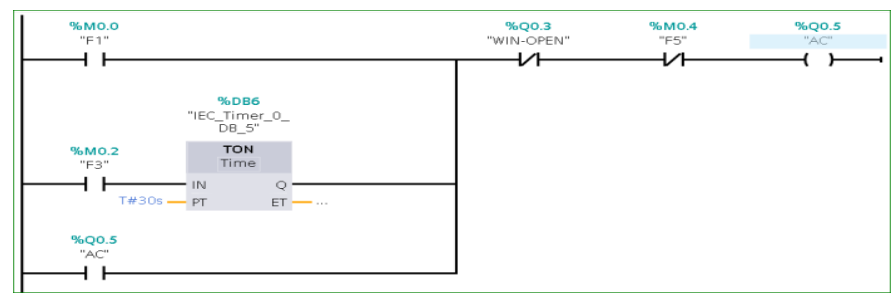

Fig. 16. Fan(s) or air condition are off

2. Close the window if there is no signal of mechanical sensitivity limit switch.

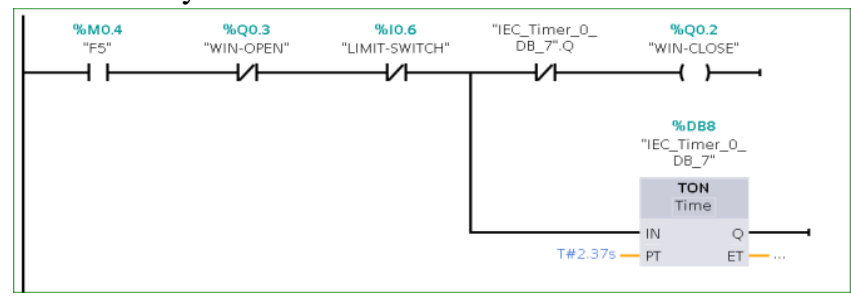

Fig. 17. Windows are shut
3. After (10 seconds) Turning off the lightning

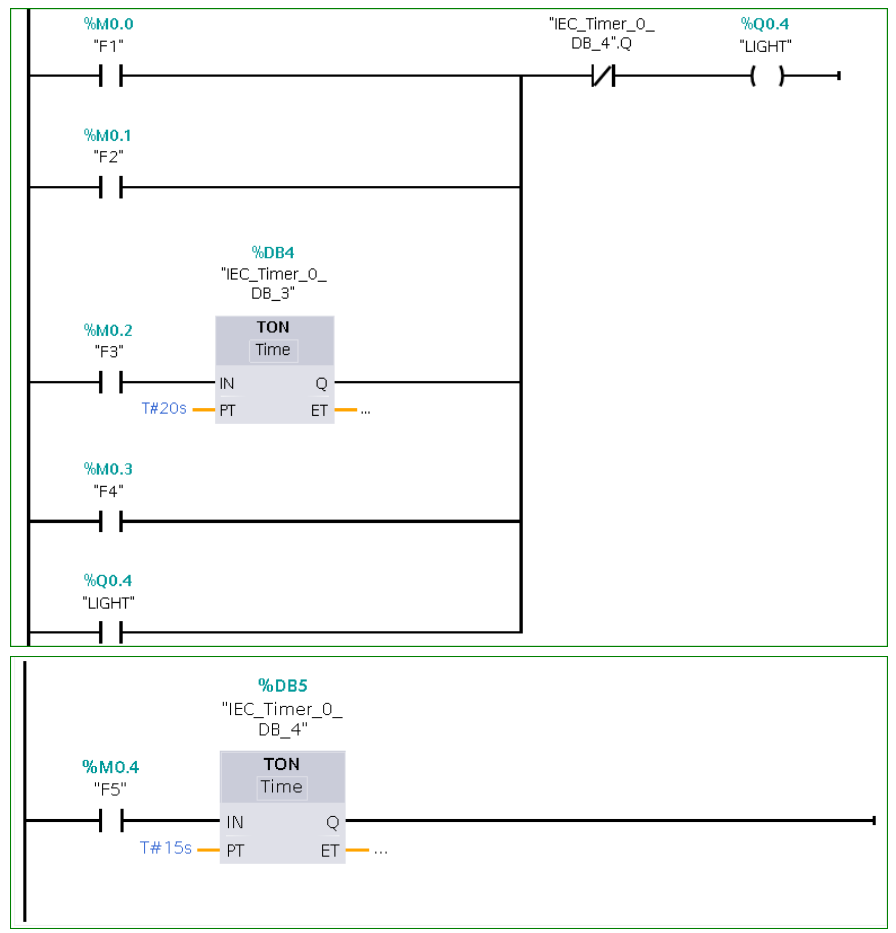

Fig. 18 lights are off in 10 seconds

4. After (10 seconds) the door is closed

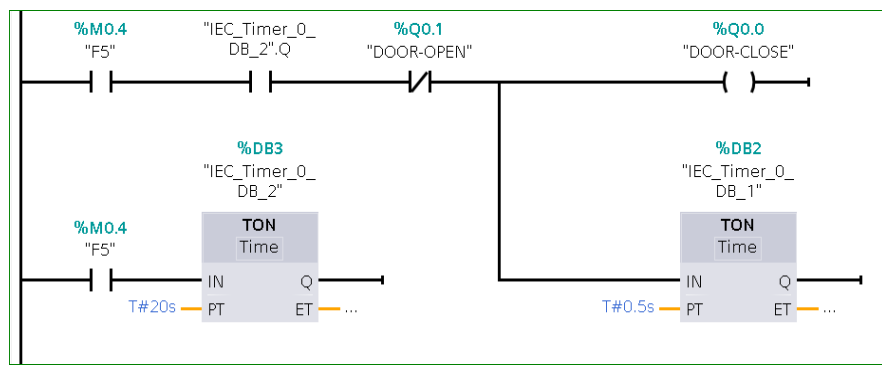

Fig. 19 door is shut it 10 seconds

It should be noted that if any of the options is selected ("A, B, C, D") any other option will not be selected the option is automatically closed and the "reset" button is pressed, then the PIN is entered, and then press "G", after which the other is activated. Fig. 20 through 22 illustrates the control flow chart of the system.

As mentioned earlier, the system works only during working hours (within 7 hours per day) with an Emergency Push Button (EPR) to shut down the entire system in case of emergency. 
International Journal of Engineering Applied Sciences and Technology, 2019

Vol. 4, Issue 6, ISSN No. 2455-2143, Pages 196-204

Published Online October 2019 in IJEAST (http://www.ijeast.com)
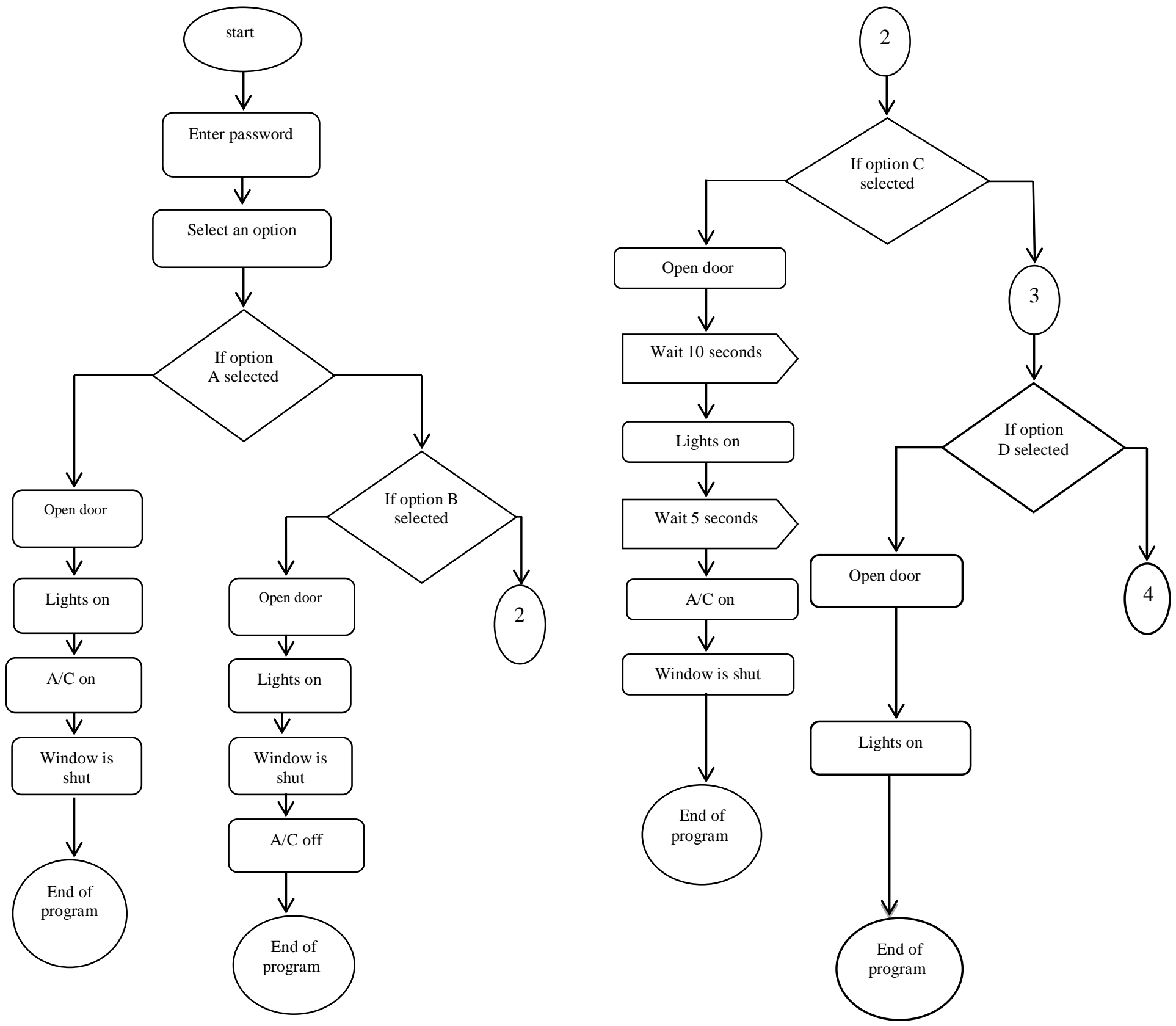

Fig. 21 The third part of the control program

Fig. 20 the first and second part of the control program 


\section{International Journal of Engineering Applied Sciences and Technology, 2019 \\ Vol. 4, Issue 6, ISSN No. 2455-2143, Pages 196-204 \\ Published Online October 2019 in IJEAST (http://www.ijeast.com)}

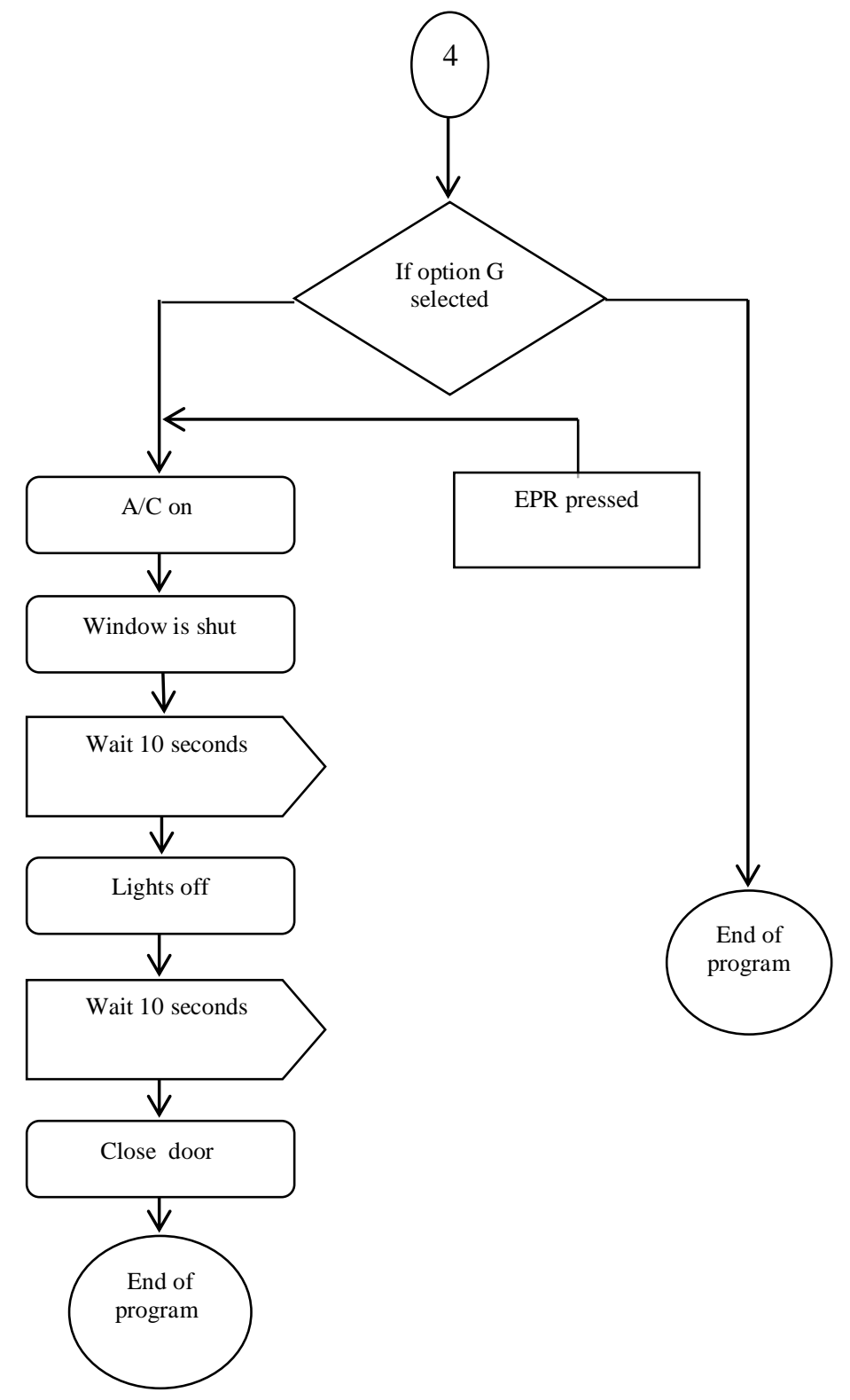

Fig. 22 The final part of the control program

\section{CONCLUSION}

In this research, a prototype for a building management system was designed and the implemented. The prototype included a door, lighting system, window, air conditioner, fan. Six options were implemented to control the conditions of door security, air-conditioning and ventilation, lights in the prototype.
The control system was based on a Siemens' programmable logic controllers PLC type (S7-1200) was used to design, simulate and generate a ladder routine program. The system was tested according to the optioned mentioned earlier with reasonable findings were presented. Evaluation of the system is yet to be conducted.

\section{REFERENCES:}

1. Bushby S. (2017). BACnetTM : a standard communication infrastructure for intelligent Buildings- Automation in Construction, Volume 6, Issues 5-6, (pp. 529-540).

2. Derek T., Celements-Croome J. (1997). What do we mean by intelligent building? -Automation in Construction, (pp.395-400).

3. Home Automation, (2016), Wikipedia article, last update, Apr $4^{\text {th }} 2017$.

4. Honold J., Kandler C., Wimmer P., Schropp B., Reichle R., Gröne M. (2017). Distributed integrated energy management systems in residential Buildings, Applied Thermal Engineering, Volume 114, (pp. 1468-1475).

5. Macarulla M., Casals M., Forcada N., Gangolells M. (2017). Implementation of predictive control in a commercial building energy management system using neural networks, Energy and Buildings, Volume 151, (pp. 511-519).

6. Oti A., Kurul E., Cheung F. , Tah J. (2016). A framework for the utilization of Building Management System data in building information models for building design and operation, ScienceDirect, Volume 72, Part 2, (pp 195-210).

7. Papantoniou S., Mangili S., Mangialenti I. (2017). Using Intelligent Building Energy Management System for the Integration of Several Systems to one Overall Monitoring and Management System, Energy Procedia, Volume 111, (pp. 639-647).

8. Puķīte I., Geipele I.(2017). Different Approaches to Building Management and Maintenance Meaning Explanation, Procedia Engineering, Volume 172, (pp. 905-912).

9. Rezeka S., Attia A., Saleh A. (2015). Management of air-conditioning systems in residential buildings by using fuzzy logic, Alexandria Engineering Journal, Volume 54, Issue 2, (pp. 91-98).

10. Smart homes (2017), Automated building, MasteryIT, Home Automation Egypt Mastery IT, last update, Apr4th 2019. 
International Journal of Engineering Applied Sciences and Technology, 2019 Vol. 4, Issue 6, ISSN No. 2455-2143, Pages 196-204

Published Online October 2019 in IJEAST (http://www.ijeast.com)

11. Yang T.,g Clements-Croome D., Marson M. (2017). Building Energy Management Systems, Encyclopedia of Sustainable Technologies, Reference Module in Earth Systems and Environmental Sciences, (pp. 291-309).

12. Wikipedia article (2016) Home Automation, last update, March $24^{\text {th }} 2017$. 